\title{
Induction of HITS, a newly identified family with sequence similarity 107 protein (FAM107B), in cancer cells by heat shock stimulation
}

\author{
HIDEO NAKAJIMA $^{1}$, YASUHITO ISHIGAKI ${ }^{2}$, QI-SHENG XIA ${ }^{1}$, TAKAYUKI IKEDA ${ }^{3}$, YOSHINO YOSHITAKE ${ }^{3}$, \\ HIDETO YONEKURA ${ }^{3}$, TAKAYUKI NOJIMA ${ }^{4}$, TAKUJI TANAKA ${ }^{4}$, HISANORI UMEHARA ${ }^{5}$, \\ NAOHISA TOMOSUGI ${ }^{2}$, TAKANOBU TAKATA $^{2}$, TAKEO SHIMASAKI $^{1}$, NAOKI NAKAYA ${ }^{1}$, ITARU SATO $^{1}$, \\ KAZUYUKI KAWAKAMI $^{6}$, KEITA KOIZUMI $^{7}$, TOSHINARI MINAMOTO ${ }^{6}$ and YOSHIHARU MOTOO $^{1}$ \\ ${ }^{1}$ Department of Medical Oncology, ${ }^{2}$ Medical Research Institute and Departments of ${ }^{3}$ Biochemistry, ${ }^{4}$ Pathology and \\ ${ }^{5}$ Hematology and Immunology, Kanazawa Medical University, 1-1 Daigaku, Uchinada, Kahoku, Ishikawa 920-0293; \\ ${ }^{6}$ Division of Translational and Clinical Oncology, Cancer Research Institute and ${ }^{7}$ Department of Biophysical Genetics, \\ Graduate School of Medical Science, Kanazawa University, 13-1 Takara-machi, Kanazawa, Ishikawa 920-0934, Japan
}

Received March 31,2010; Accepted May 14, 2010

DOI: 10.3892/ijo_00000707

\begin{abstract}
The Family with sequence similarity 107 (FAM107) possesses an $\mathrm{N}$-terminal domain of unknown function (DUF1151) that is highly conserved beyond species. In human, FAM107A termed TU3A/DRR1 has been reported as a candidate tumor suppressor gene which expression is downregulated in several types of cancer, however no studies have investigated the other family protein, FAM107B. In the present study, we designated FAM107B as heat shockinducible tumor small protein (HITS) and studied its expression and functional properties in cancer. HITS is an $18-\mathrm{kDa}$ nuclear protein expressed in a variety of tissues including stomach, colon, lung and lymphoid organs. In human gastric and colorectal cancers and a mouse model of colon cancer, its expression in tumor cells was much lower than normal epithelial cells, while expression pattern and intensity varied among different histological types of cancer. In functional analysis in vitro, forced expression of this protein suppresses the cellular responses to growth factors. Furthermore, HITS gene carries the promoter region providing heat shock transcription factor (HSF) binding sites and amplifying the transcription of HITS by heat shock or hyperthermia treatment both in vitro and in vivo. Thus HITS would be a potential tumor suppressor gene similar to TU3A containing heat responding elements, which contrasts with previously described oncogenic activities of other heat shock proteins such as HSP70 and HSP90.
\end{abstract}

Correspondence to: Dr Hideo Nakajima, Department of Medical Oncology, Kanazawa Medical University, 1-1 Daigaku, Uchinada, Kahoku, Ishikawa 920-0293, Japan

E-mail: hideonak@kanazawa-med.ac.jp

Key words: FAM107, TU3A, heat shock protein, tumor suppressor gene

\section{Introduction}

The Family with sequence similarity 107 (FAM107) possesses an N-terminal domain of unknown function (DUF1151) that is conserved beyond species including mammalian, Xenopus, fish and Drosophila, and shows no homology match to other functional conserved domains (http://www.ncbi.nlm. nih.gov/structure/cdd/cdd.shtml). This family includes several hypothetical eukaryotic proteins of unrevealed function. In mammals, FAM107 consists of two genes FAM107A and FAM107B, coding proteins of 144 amino acids (aa) and 131 aa respectively (http://www.uniprot.org/uniprot).

FAM107A designated TU3A (Tohoku University cDNA clone A on chromosome 3), also called DRR1 (down-regulated in renal cell carcinoma gene 1) is a candidate tumor suppressor gene located on chromosome 3p21.1 (1,2). Recently several studies have reported that TU3A expression is downregulated in a variety of cancers by epigenetic silencing such as promoter hypermethylation (3-5). In addition, the reexpression of TU3A suppresses cancer cell growth and induces apoptosis $(2,6)$.

In this study, we examined expression, tissue localization and functional properties of FAM107B, and designated FAM107B as heat shock-inducible tumor small protein (HITS) because of its unique expression pattern in cancer cells and relatively small molecular weight $(18 \mathrm{kDa})$ among heat shock proteins (HSPs). In human, HITS protein is encoded by the gene on chromosome 10p13 and consists of 131 aa, the sequence of which is almost $98 \%$ identical with mouse and rat homologues. FAM107A (TU3A) and FAM107B (HITS) proteins share $65 \%$ sequence similarity in their DUF1151 regions. At present, no functional information is available for HITS despite recent accumulating data on TU3A. Herein, we demonstrate heat shock-inducible unique expression pattern and biological properties of HITS in cancer cells, that is distinct from other HSPs equipped with oncogenic activities $(7,8)$. 


\section{Materials and methods}

Cells and tissue specimens. HEK293 and HeLa cells were cultured in DMEM with $10 \%$ fetal calf serum (FCS), and THP-1 and Jurkat cells in RPMI-1640 with 10\% FCS. HITS cDNA was subcloned into pcDNA3.1 D/V5-His-TOPO (Invitrogen, CA) and transfected into 293 cells using Lipofectamine 2000 reagent (Invitrogen) to express HITS-V5-His fusion protein. Stable transfectants were obtained through selection by neomycin. Inducible expression of HITS was generated by Tet-On advanced inducible gene expression system (Clontech, CA). Full-length cDNA of HITS was introduced into a retrovirus vector, pRetroX-Tight Pur, with a Tet-inducible promoter. Virus stock was prepared by transfecting vector plasmid into GP2-293 packaging cells (Clontech) and then infected to the HeLa Tet-On advanced cell line (Clontech). For selecting stable transfectants (HeLaTet-HITS or control HeLa-Tet-MOCK), infected cells were cultured in the medium containing puromycin.

Matched pairs of fresh non-neoplastic (normal) and tumor tissues were obtained from the surgical specimens of stomach and colorectal cancer patients (9). Each patient signed an informed consent form. These tissue samples were stored in $-80^{\circ} \mathrm{C}$ till use for extraction of total RNA. Surgical specimens were then fixed in neutral-buffered $10 \%$ formalin, embedded in paraffin and processed for histopathological diagnosis and immunohistochemical examinations. Histological types of stomach and colorectal cancers were classified according to the WHO Classification $(10,11)$. Paraffin sections of normal brain, thyroid, thymus, lung, esophagus, liver, pancreas, uterus, prostate and lymph node were prepared from autopsy cases. This study was approved by the Institutional Review Boards of Kanazawa Medical University and Kanazawa University.

Colon carcinogenesis mouse model. Crj:CD-1 (ICR) male mice at 5-week-old (Charles River Japan) received a single intraperitoneal injection of azoxymethane (AOM) at a dose of $10 \mathrm{mg} / \mathrm{kg}$ body weight. Starting 1 week after the AOM injection, mice were exposed to $2 \%$ dextran sodium sulfate (DSS) in the drinking water for 7 days (12). They were autopsied at the week 12. The histopathological findings of the large bowel lesions were examined by hematoxylin and eosin (HE)-staining and immunohistochemistry. The animal study was conducted according to the Guidelines for Experimental Animals at Kanazawa Medical University and the National Guidelines for Animal Usage in Japan (http://www.lifescience. mext.go.jp/policies/pdf/an_material011.pdf).

Antibodies. Anti-V5 (Invitrogen), anti-HSP90 (Stressgen, MI), anti-Lamin A/C and anti- $\beta$-actin (Santa Cruz Biotech, CA) antibodies (Abs) were purchased. To generate anti-HITS anti-serum, rabbits were immunized with KLH-conjugated polypeptides MAEPDYIEDDNPE. The anti-serum was purified by affinity chromatography against the polypeptides cross-linked to agarose beads.

Immunostaining. Cultured cells were fixed with $2 \%$ paraformaldehyde and permealized by $0.5 \%$ Triton-X. After blocking with $2 \%$ FCS, cells were stained with fluorescein isothiocyanate (FITC)-conjugated anti-V5 Ab or anti-HITS rabbit serum plus FITC-conjugated secondary $\mathrm{Ab}$, and then subjected to FACS or fluorescence microscope analysis.

Expression and localization of HITS and HSP90 in paraffin sections of tissues were observed by immunohistochemical examinations using the avidin-biotin-peroxidase complex $(\mathrm{ABC})$ method. Microwaved tissue sections were incubated with the respective antibodies (1:500 dilution each) overnight at $4^{\circ} \mathrm{C}$, followed by the standard procedure (13).

Complementary DNA synthesis and semi-quantitative RT-PCR. Total RNA was isolated from cultured cells and fresh surgical tissues with RNeasy mini kits (Qiagen, Germany) according to the manufacturer's instruction, and a $10 \mu \mathrm{g}$ aliquot of total RNA was subjected to cDNA synthesis using First-Strand cDNA synthesis kit (Amersham, UK). Mixtures containing $1 \mu 1$ of synthesized cDNA were amplified by PCR for 25 cycles $\left(94^{\circ} \mathrm{C}\right.$ for $30 \mathrm{sec}, 50^{\circ} \mathrm{C}$ for $30 \mathrm{sec}, 72^{\circ} \mathrm{C}$ for $\left.30 \mathrm{sec}\right)$ after denaturation for $2 \mathrm{~min}$ at $94^{\circ} \mathrm{C}$. The primer pairs for RT-PCR are listed below: HITS forward: 5'-AGCACAGAAGAAGA AATCTGA-3'; HITS reverse: 5'-CTTGGGCGACTTCTTGG CCTG-3'. B-actin forward: 5'-ACACTGTGCCCATCTACG AGGGG-3'; ß-actin reverse: 5'-ATGATGGAGTTGAAGGT AGTTTCGTGGAT-3'.

DNA microarray analysis. Total RNAs from heat shocktreated and non-treated Jurkat cells were subjected to cRNA preparation using a MessageAmp $\mathrm{II}^{\circledR}$-Biotin Enhanced Kit (Ambion, TX). Target hybridizations were performed using a Human Genome U133 plus 2.0 Gene-Chip microarray system (Affymetrix, UK). The hybridized cRNAs were detected using a GeneChip ${ }^{\circledR}$ Scanner 3000 . The digital data were processed using the GeneChip Operating Software (GCOS) version 1.4.

Western blot analysis. To obtain nuclear and cytoplasmic extracts, cultured cells were treated with NucBuster Protein Extraction kit (Novagen, Germany) according to the manufacturer's instruction, and extracts from $3 \times 10^{5}$ cells were separated by standard sodium dodecylsufate (SDS)-polyacrylamide gel electrophoresis (PAGE) and transferred to polyvinylidene difluoride membranes (Amersham). Membranes were probed with the respective primary antibodies, followed by a horseradish peroxidase-conjugated secondary antibody and developed using chemiluminescence (Amersham).

Drug resistance. HeLa-Tet-MOCK and -HITS transfected cells were suspended in DMEM containing $10 \%$ FCS with or without $1 \mu \mathrm{g} / \mathrm{ml}$ doxycycline, and 5000 cells/well were seeded and treated with paraquat $(1-5 \mu \mathrm{M})$, etoposide $(30,100 \mu \mathrm{M})$, 5 -FU $(160,320 \mu \mathrm{g} / \mathrm{ml})$ or CDDP $(10,20 \mu \mathrm{M})$. After treatment for 2 days, relative number of viable cells was measured by MTT assay using Cell Counting Kit-8 (Dojin, Japan), and cell survival was calculated by the ratio against untreated cells.

Cell responses to growth factors. HeLa-Tet-MOCK and -HITS transfected cells were suspended in DMEM containing 0.2\% FCS with or without doxycycline, and 5000 cells/well were seeded in 96-well plates. After serum depletion for 2 days, human recombinant fibroblast growth factor-2 (FGF-2), 


\section{A}

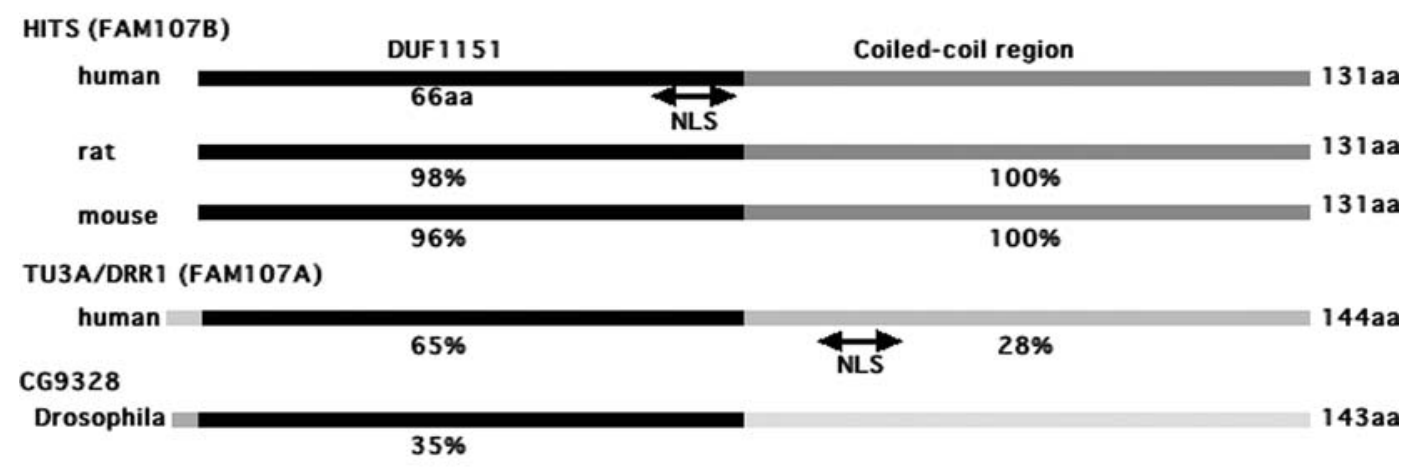

B

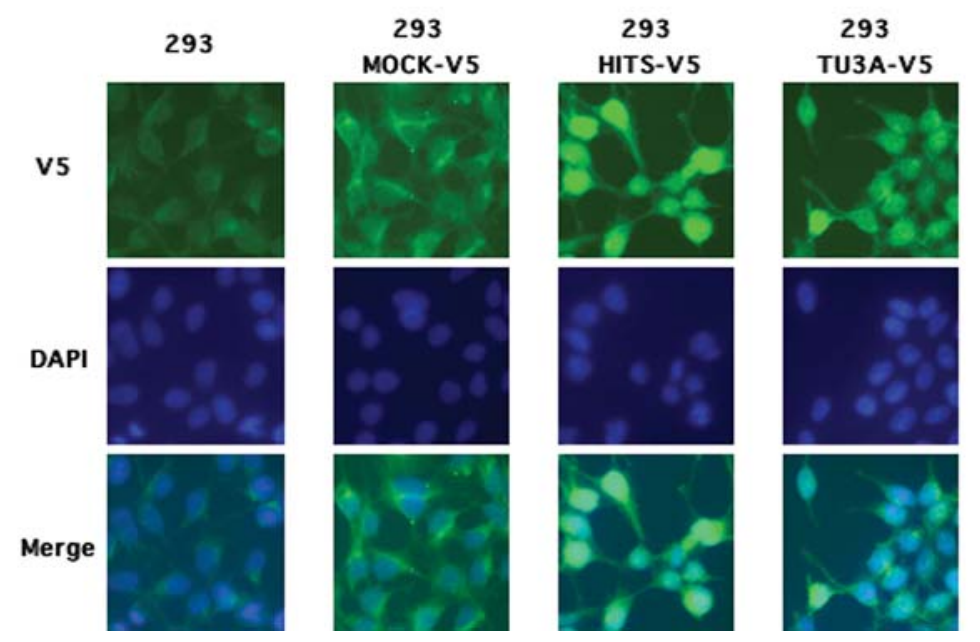

Figure 1. Molecular structures of FAM107 family proteins and subcellular localization of HITS (FAM107B) and TU3A (FAM107A) proteins. (A) Molecular structure of FAM107 family of proteins was compared among different species. In rat and mouse HITS, human TU3A/DRR1 and Drosophila CG9328, homology of each protein to human HITS protein sequence is shown by \%. NLS, nuclear localization signal. (B) Fusion proteins of HITS and TU3A tagged with V5 (HITS-V5 and TU3A-V5, respectively) were expressed in 293 cells. As controls, untransfected 293 cells and those transfected with empty insert (MOCK-V5) were examined. These cells were immunostained with FITC-labeled anti-V5 antibody. Nuclei were counterstained with DAPI. A merged image is generated in each cell type.

epidermal growth factor (EGF) (both from Wako Pure Chemical, Japan) or increased amount of FCS were added to octuplicate wells at indicated concentrations. Proliferation of cells after 2 days of stimulation was measured by MTT assay as described above.

Luciferase assay. According to the published genomic sequences, 5'-flanking region of HITS $(-316$ to +189$)$ was amplified and ligated into pGL3-Basic vector (Promega, WI) to generate a HITS promoter-firefly luciferase reporter construct (pGL3-HITS). As previously described, pGL3-Basic or pGL3-HITS and pRL-thymidine kinase control vector (pRL-TK; Promega) were transfected to 293 cells (14). Next day, the cells were harvested after heat shock treatments and assayed by the Dual-Luciferase Assay System (Promega), using a luminometer. The relative light units were calculated after normalization against Renilla luciferase activities of the pRL-TK internal control vector.

Hyperthermia and heat shock treatment. For heat shock stimulation, cultured cells were incubated at $42^{\circ} \mathrm{C}$ for $2 \mathrm{~h}$, followed by recovery at $37^{\circ} \mathrm{C}$ for indicated periods. Then the cells were harvested and processed for luciferase assay, RTPCR, Western blotting or DNA microarray analysis.
For hyperthermia treatment of rat tumor model, Rat Walker 256 sarcoma was subcutaneously inoculated at a flank of Sprague-Dawley Rats. When tumors grew to $\sim 2 \mathrm{~cm}$ in diameter, hyperthermia treatment was performed on an air heating machine with a spray tube that can cover the tumor area of the rat (AOYUE 615, Tongyi Electronic Equipment Factory, Zhongshan City, China). Heated air was ejected from this tube and the flow was adjusted manually. The temperature at the center of tumor was monitored by thermocouples (Physitemp, NJ). The air flow of the heating machine was adjusted and kept at $43^{\circ} \mathrm{C}$ for $2 \mathrm{~h}$. Tumor tissues were removed $6 \mathrm{~h}$ later and processed for histopathological and immunohistochemical examinations.

Statistical analysis. Between-group statistical significance was determined using Student's t-test. $\mathrm{P}<0.05$ was considered as statistically significant.

\section{Results}

Expression and subcellular localization of HITS in normal tissues. The FAM107 family of proteins share homology in an N-terminal domain that is conserved among species (Fig. $1 \mathrm{~A})$. According to the protein data base, FAM107B protein 
A anti-HITS rabbit Ab
FITC $\quad+$ anti-rabbit IgG-FITC
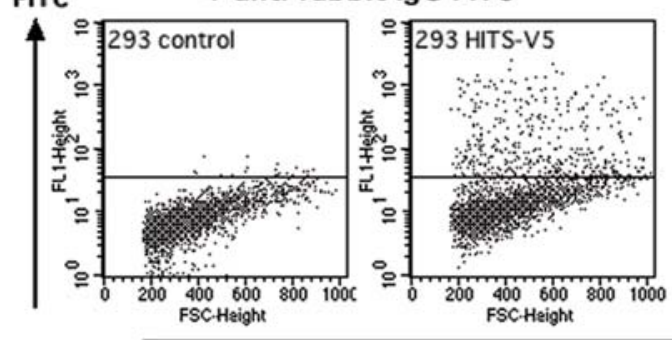

anti-V5-FITC

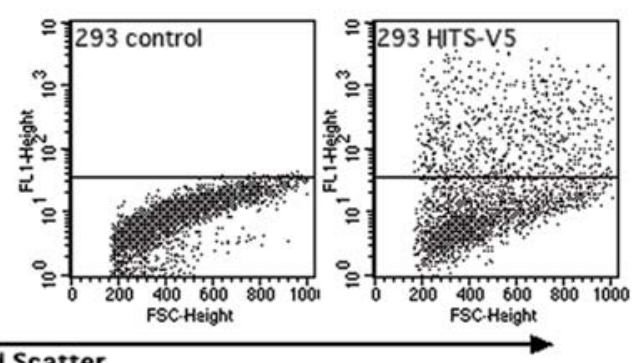

B

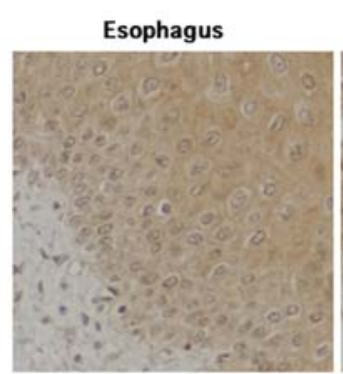

Liver
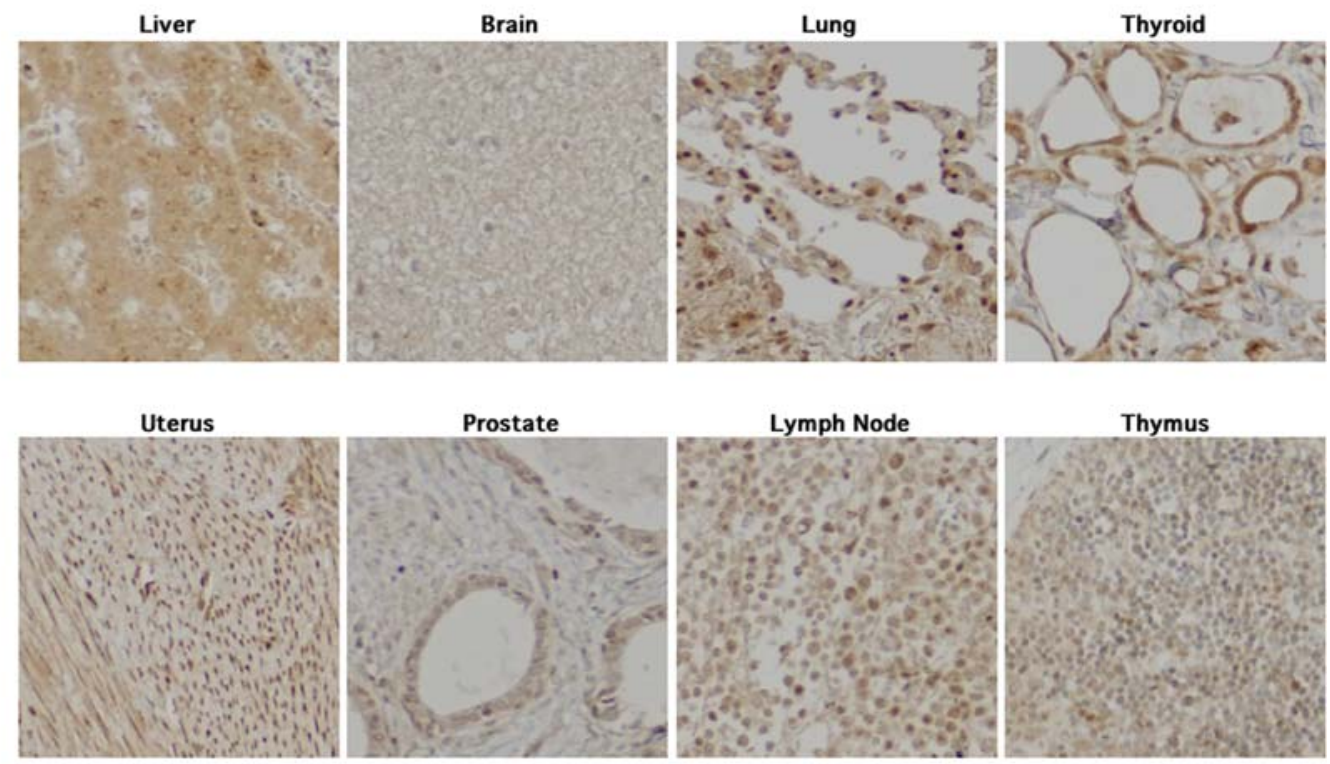

Prostate
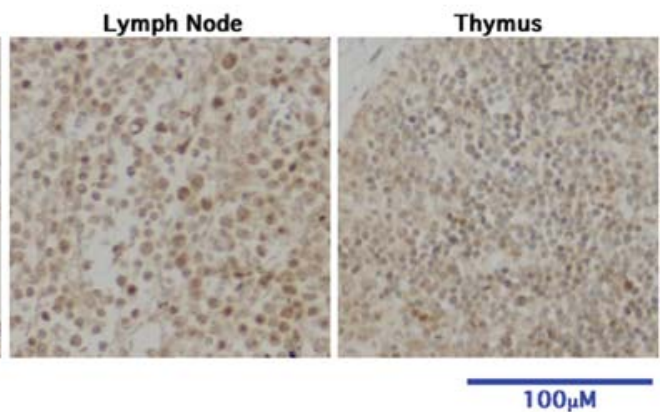

Figure 2. Characterization of the polyclonal antibody to HITS protein and immunohistochemical examination of expression and localization of HITS protein in normal human tissues. (A) To test specificity of the antibody against human HITS, 293 cells transiently transfected with pcDNA3.1 HITS-V5-His (293 HITS-V5) or control pcDNA3.1 V5-His (293 control) were immunostained with the purified anti-HITS antibody or anti-V5 monoclonal antibody. The stained cells were analyzed by FACS. X-axis, forward scatter; Y-axis, FITC (anti-rabbit IgG-FITC or anti-V5-FITC). (B) Immunohistochemical analysis of HITS expression. Paraffin sections of various human normal tissues were immunostained with anti-HITS antibody.

(UniProtKB/Swiss Prot: Q9H098) has a 131 aa sequence length which consists of an N-terminal (aa 1-66) conserved domain DUF1151 and a C-terminal (aa 61-112) variable coiled-coil region. Both FAM107A (TU3A) and FAM107B (HITS) have a nuclear localization signal (NLS) in the center of the protein sequences (Fig. 1A). Intracellular localization of HITS was determined by immunostaining of HITS-V5 fusion protein expressed in 293 cells with FITC-labeled antiV5 Ab. As well as TU3A, which has been reported to be a nuclear protein, HITS was localized in the nuclear portion since its fluorescence signals largely coincided with DAPI signals (Fig. 1B).
To investigate the expression and localization of HITS in normal human tissues, antibody against HITS was generated and verified its specificity by FACS (Fig. 2A) and Western blot analysis (Fig. 5A). Immunohistochemical examinations revealed that HITS was expressed in a broad range of normal tissues. In particular, intense immunoreactivity of antibody was observed in nuclei of colon, stomach and lung epithelial cells (Fig. 2B).

Expression of HITS in gastrointestinal tumors. As TU3A expression is reported to be downregulated in several human cancer types $(1,2)$, we investigated the expression of HITS 
A

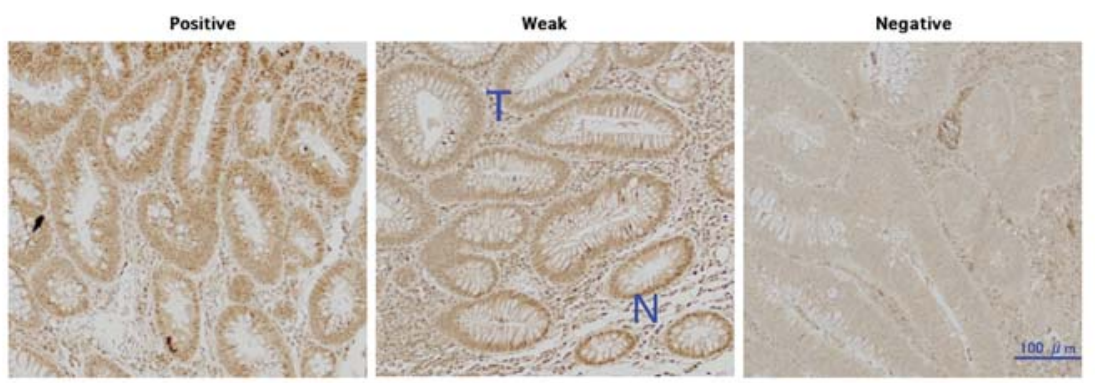

B
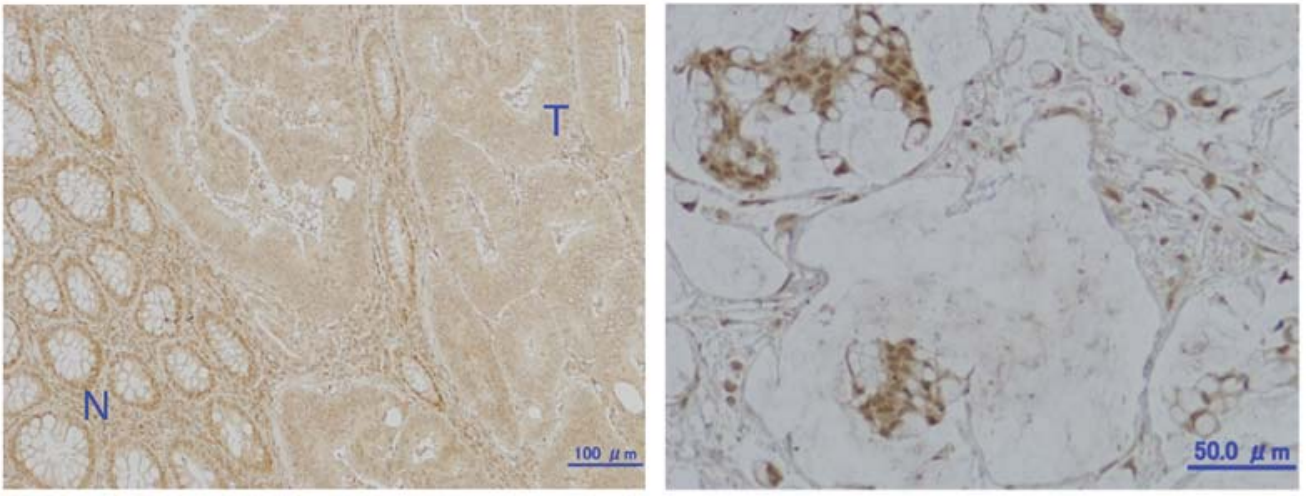

C
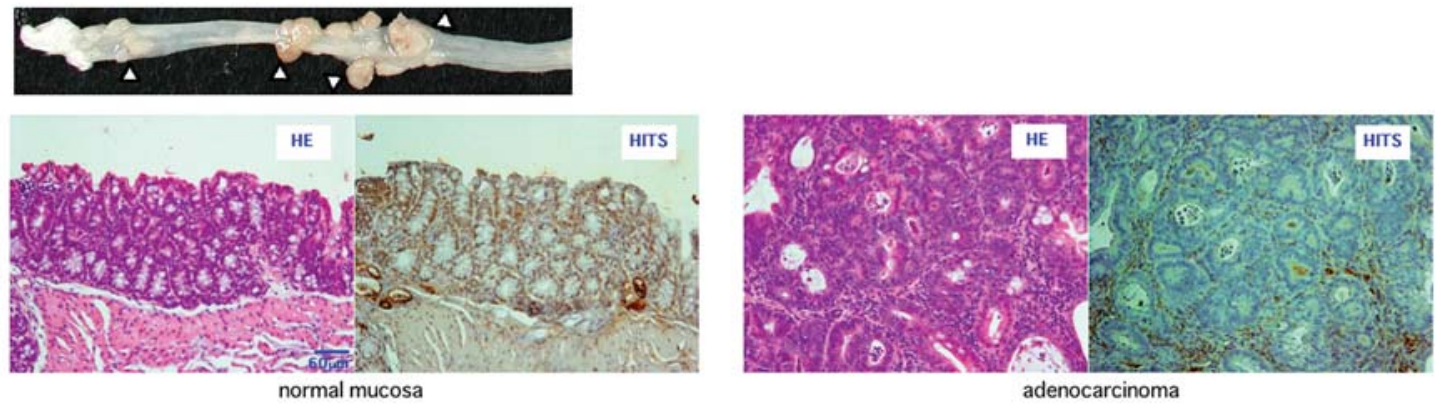

Figure 3. Expression of HITS in human colorectal tumors and colon cancer in a mouse model. (A) Expression of HITS in tubular adenoma of the human colon. Levels of HITS expression were classified into 3 categories, positive, weak ( $\mathrm{T}$, adenoma; N, normal mucosa) and negative, as defined in the text. (B) Expression of HITS was negative in a well differentiated adenocarcinoma (T) and positive in adjacent normal mucosa (N) (left) and in a mucinous adenocarcinoma (right) of human colon. The results are summarized in Table I. (C) Gross finding of a large bowel removed from an AOM-induced colon carcinogenesis model mouse (upper panel) showed multiple protruding tumors (arrow heads). Serial sections of non-neoplastic (normal) mucosa and adenocarcinoma were stained with HE and immunostained with anti-HITS antibody, respectively (lower panels). Note that no expression of HITS was found in adenocarcinoma cells.

in stomach and colorectal tumors (Figs. 3 and 4). Levels of HITS protein expression in tumor tissues were classified into 3 categories, positive (comparable to normal epithelium), weak (expressed less than normal counterpart) and negative (no expression) (Fig. 3A). Human colorectal adenomas (22 cases) and adenocarcinomas (52 cases) were immunohistochemically analyzed, and the results are summarized in Table I. While more than half of adenomas were positive, only $6 \%$ of adenocarcinomas were positive for HITS expression. Two of three HITS-positive carcinomas were histologically mucinous adenocarcinomas (Fig. 3B right and Table I). In AOM induced colon carcinogenesis mouse model, HITS expression was markedly decreased in carcinoma cells (Fig. 3C). Thus, HITS expression was downregulated in association with the progression of colon carcinogenesis.

HITS showed a distinct expression pattern in gastric carcinomas that were histologically classified into two major groups (15). In most of intestinal type gastric carcinomas, expression of HITS was negative or weak (Fig. 4A and Table I) as defined above, while its expression in $>80 \%$ of diffuse type carcinomas was comparable to the foveolar ducts in the matched normal mucosa (Fig. 4B and Table I). Staining in mixed type of intestinal and diffuse carcinoma clearly represents this specificity of HITS expression pattern (Fig. 4C). Since the classification of HITS expression level in mixed type is difficult to judge, it is excluded from the sum in Table I. Mucinous adenocarcinoma was positive for expression of HITS, similar to colon mucinous adenocarcinoma (Fig. 3B right and 4D). Consistent with immunohistochemical observation, semi-quantitative RT-PCR analysis showed that HITS mRNA expression was negative or weak in intestinal type and positive in diffuse type adenocarcinomas (Fig. 4E).

Functions and biological properties of HITS in cancer cells. To clarify the functional properties of HITS protein, we employed an approach to tetracycline inducible expression system (Tet-ON). Human cervical cancer cell line, HeLa, was transfected with tetracycline-inducible expression 


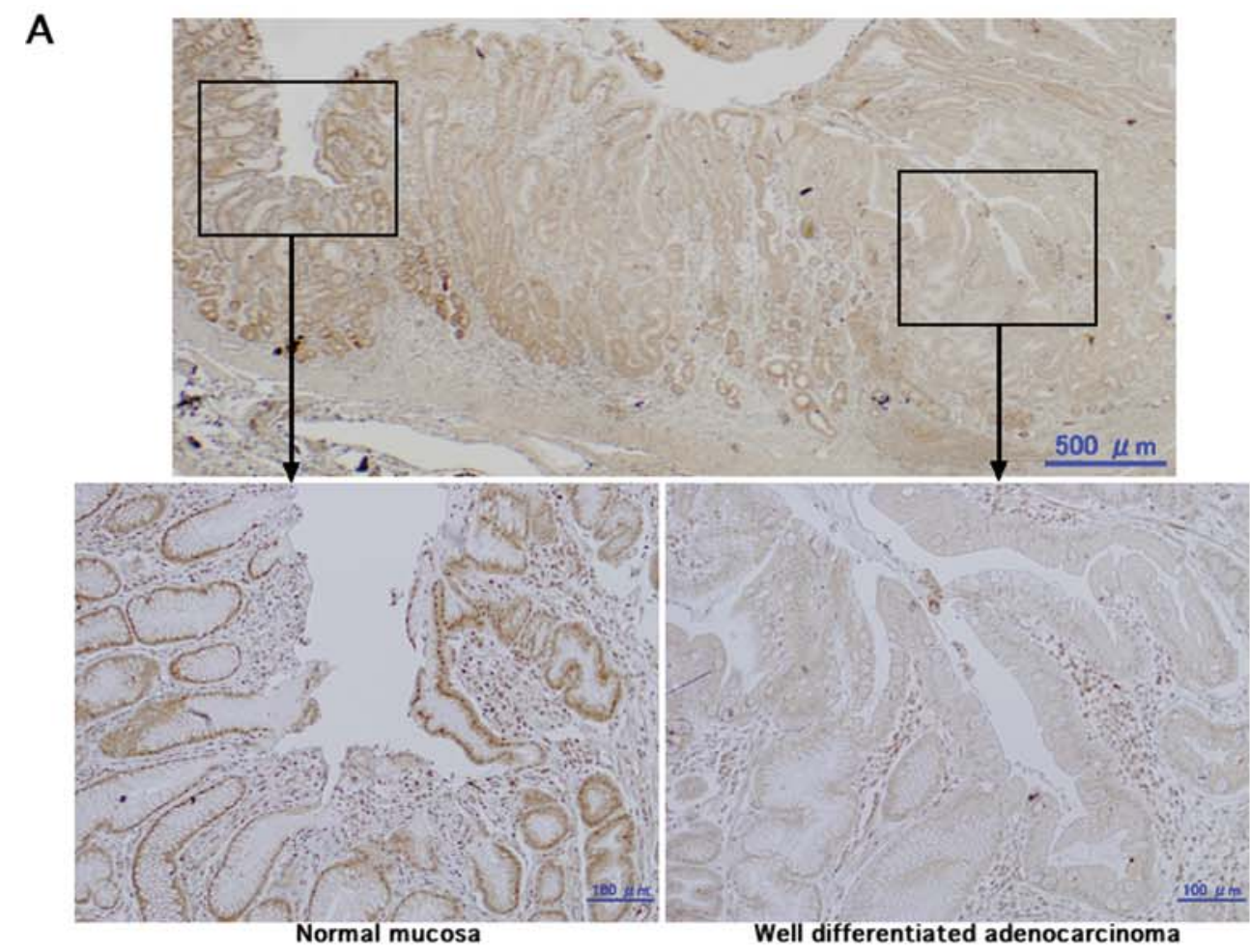

B
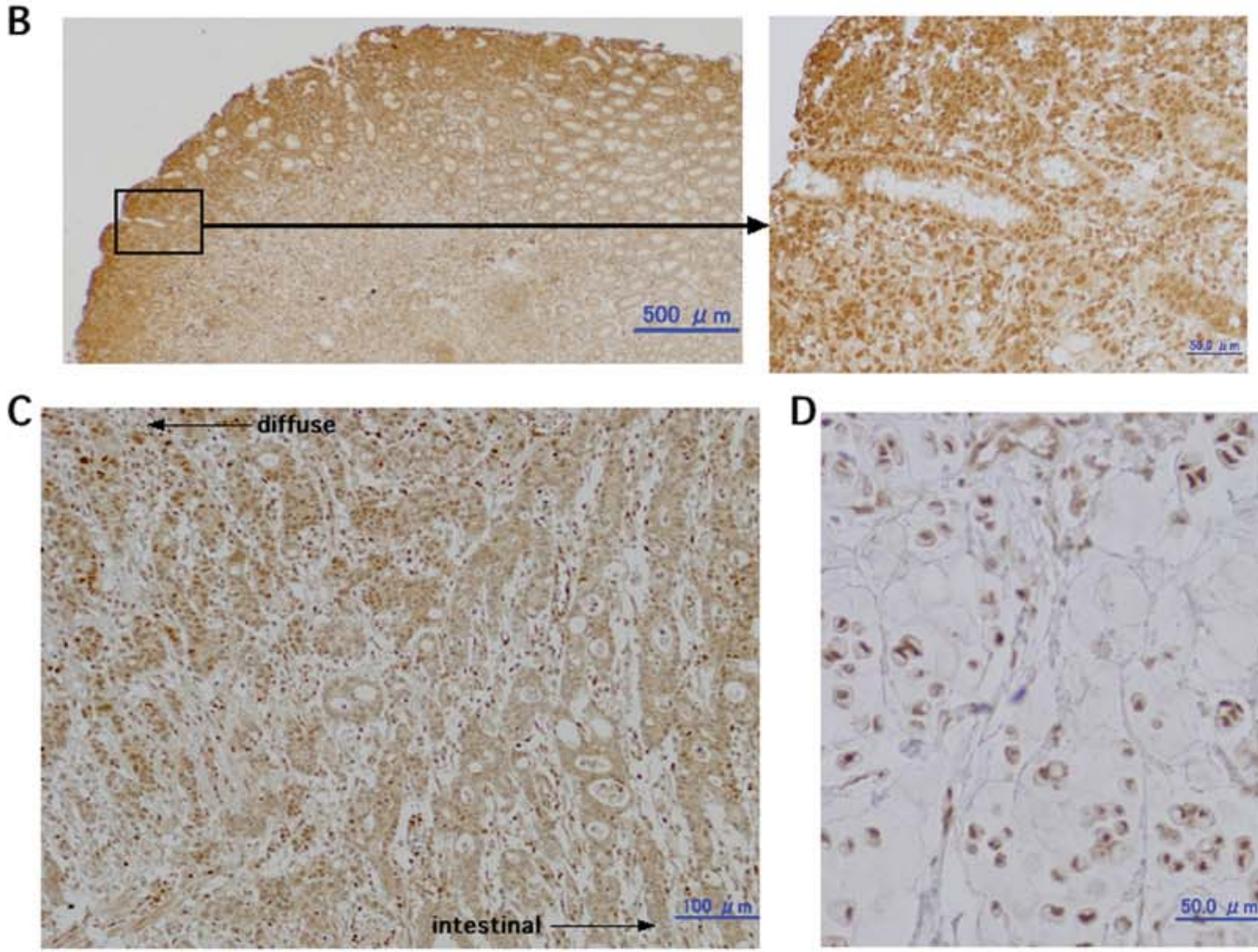

E
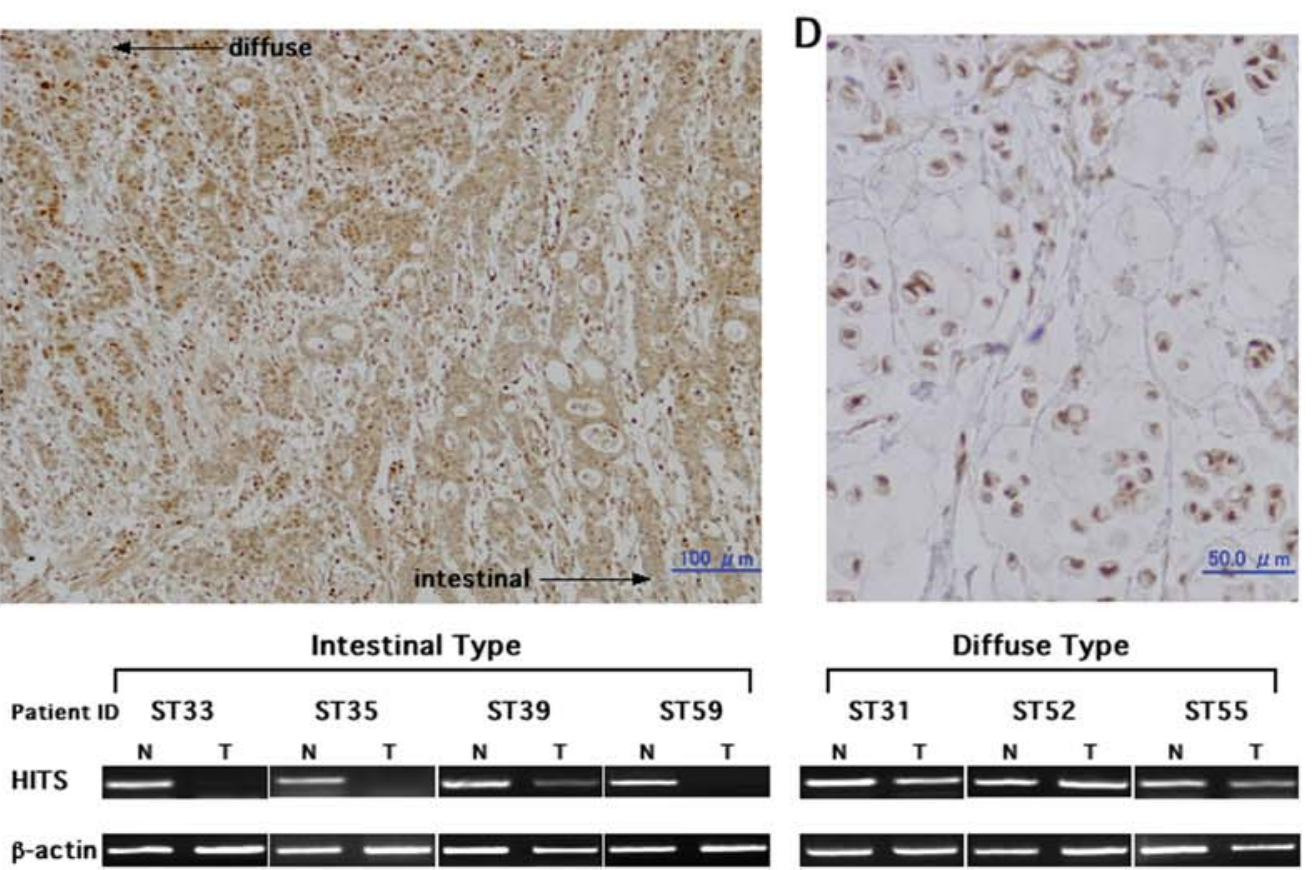

Figure 4. Expression of HITS protein and mRNA in human gastric cancer. Immunohistochemical expression of HITS protein was examined in intestinal type (A), diffuse type (B), mixed type of both intestinal and diffuse (C), and mucinous (D) adenocarcinomas. Higher magnification images of the squared regions are shown in (A) and (B). The results are summarized in Table I (mixed type is excluded from the sum). (E) Semi-quantitative RT-PCR analysis of HITS mRNA expression in the matched pairs of normal $(\mathrm{N})$ and tumor $(\mathrm{T})$ tissues obtained from the patients with intestinal type and those with diffuse type gastric adenocarcinomas, respectively. Amount of cDNA in each sample was monitored by B-actin mRNA expression. 
Table I. Expression of HITS protein in human stomach and colorectal tumors.

HITS expression in tumor

\begin{tabular}{|c|c|c|c|c|c|c|}
\hline Organ & Tumor type & Histological types & No. of cases & Positive (\%) & Weak $(\%)$ & Negative $(\%)$ \\
\hline \multirow{5}{*}{$\begin{array}{l}\text { Colon and } \\
\text { rectum }\end{array}$} & Tubular adenoma & & 22 & $13 \quad(59)$ & $8(36)$ & $1 \quad(5)$ \\
\hline & Adenocarcinoma & $\mathrm{W} / \mathrm{D}$ & 14 & $0 \quad(0)$ & $7(50)$ & $7 \quad(50)$ \\
\hline & & $\mathrm{M} / \mathrm{D}$ & 33 & $1 \quad(3)$ & $13(39)$ & $19 \quad(58)$ \\
\hline & & Muc & 4 & $2(50)$ & $2(50)$ & $0 \quad(0)$ \\
\hline & & $\mathrm{U} / \mathrm{D}$ & 1 & $0 \quad(0)$ & $0 \quad(0)$ & $1(100)$ \\
\hline \multirow[t]{3}{*}{ Stomach } & Adenocarcinoma & Intestinal & 22 & $1 \quad(3)$ & $9(41)$ & $12(55)$ \\
\hline & & Diffuse & 12 & $10 \quad(83)$ & $2(17)$ & $0 \quad(0)$ \\
\hline & & Muc & 2 & $2(100)$ & $0 \quad(0)$ & $0 \quad(0)$ \\
\hline
\end{tabular}

aHistological types according to WHO Classification $(10,11)$. M/D, moderately differentiated; Muc, mucinous; U/D, undifferentiated; W/D, well differentiated.

A

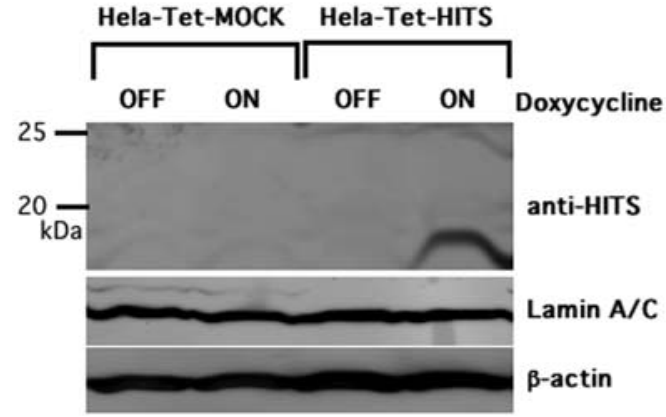

B

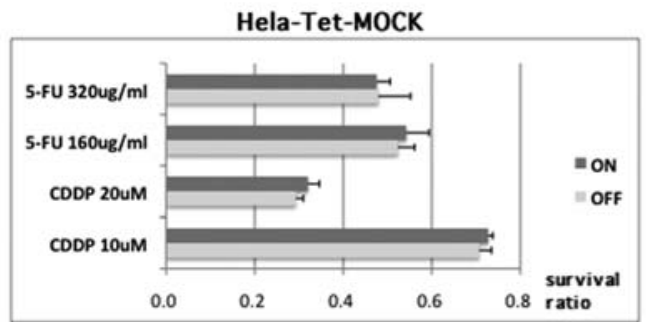

Hela-Tet-HITS

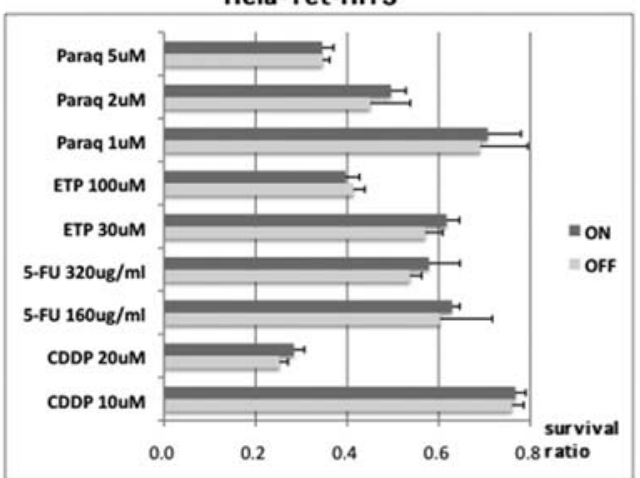

C
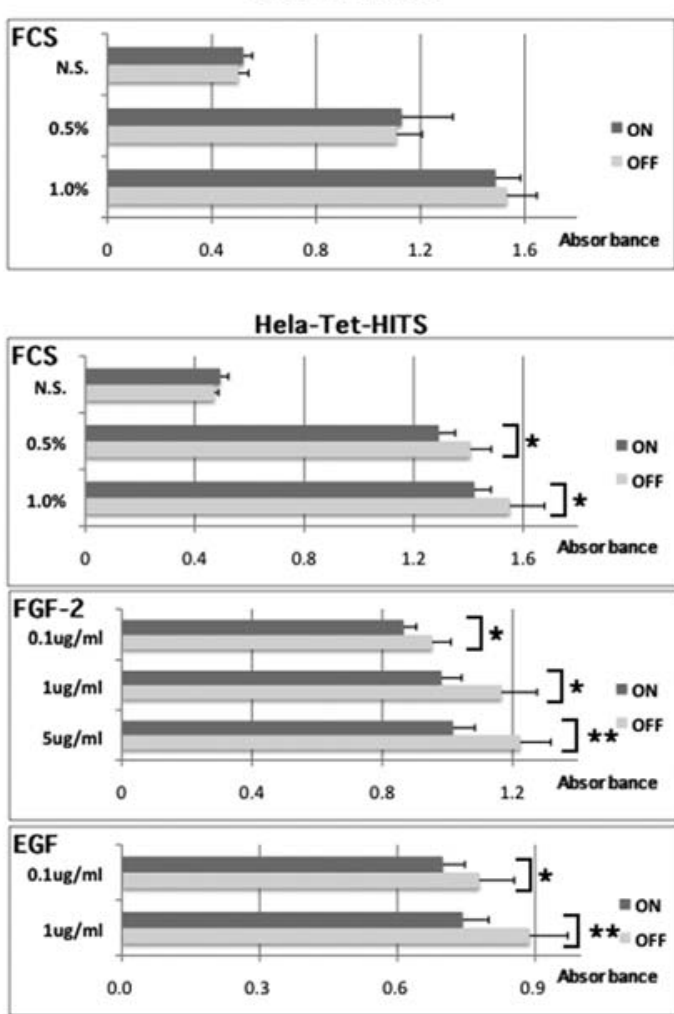

]$\star p<0.05 \quad] \star * p<0.01$

Figure 5. Generation of HeLa cells with tetracycline (Tet)-inducible expression of HITS and the effects of the inducible expression of HITS on tumor cells sensitivities to the drugs and their responses to growth factors. (A) Protein samples prepared from HeLa-Tet-HITS and HeLa-Tet-MOCK cells treated with (ON) or without (OFF) $1 \mu \mathrm{g} / \mathrm{ml}$ doxycycline were examined for expression of HITS, Lamin A/C (nuclear protein control) and B-actin by Western blot analysis. (B) Effects of HITS on HeLa cell sensitivity to the drugs. HeLa-Tet-MOCK and -HITS cells with (ON) or without (OFF) doxycycline were treated with paraquat, etoposide, 5-FU or CDDP at indicated concentrations. After treatment for 2 days, relative cell survival was calculated by the ratio against untreated cells in MTT assay. (C) Effects of HITS on HeLa cells responses to growth factors. HeLa-Tet-MOCK and -HITS cells with (ON) or without (OFF) doxycycline were maintained under serum depletion for 2 days, and then cultured with FCS $(0.5,1.0 \%)$, human recombinant FGF-2 $(0.1-5 \mu \mathrm{g} / \mathrm{ml}), \mathrm{EGF}(0.1-1 \mu \mathrm{g} / \mathrm{ml})$ and no growth factor (NS). Cell proliferation after 2 days of treatment was measured by MTT assay. In (B) and (C), values are mean \pm standard deviations in octuplicates. 
A

ITACCITTCA AAGGTCCCAC CTCCAMATAC TGTCACTITG GGGGTTAGGG CITCAACATA
$\mathbf{3 1 8}$ GGAATITIGG GGGGACTCAG CATTCAGTCG GTGTGTGTGC GTGTGTGTGT GCGTGTGTGT GCGTGTGCAT GTGTACTTGT AGAGGAGGGT TGATTGTCCA CCTGACAGCC GITGCCATCC СCTCTTCCCT GCTGGATGCC AATTTGCATT IITCTGGCAC GITTTGCGGC TAGAGTGGTC ATGTGACACT GITCTGGCCA ATGAGGCGAT GGAGGAGGC CCCCGGGGGC TICTGGGAGT GCCTGCCTTC GCAGCTGGEA GAGCCCTCCT CAGGGGCTGT CTCTGCCTTC CCITCTTCCC ATGTGTATCT GGGGCAGCTG AGGCAGGGCT AGGAGAGAG CCCAGGTTCC TCCTGCCACC TCCAAGCGAT GAAGCAGCCC TGGGCCAACT CCAGCATTCT CGTGTGAACT GCAGAGGAGC CCTGCGCTTC CAGCTACTTG CAGCCAG
+189

B

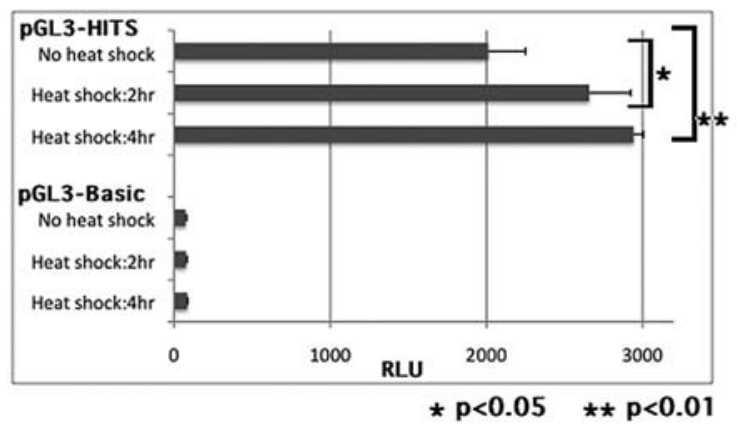

C

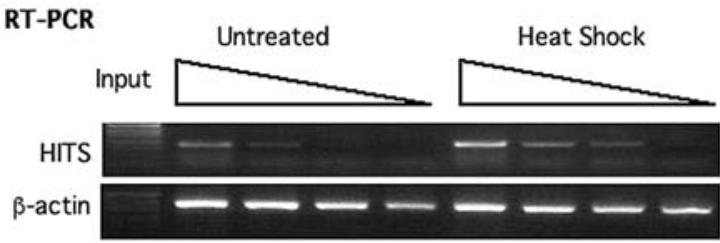

D

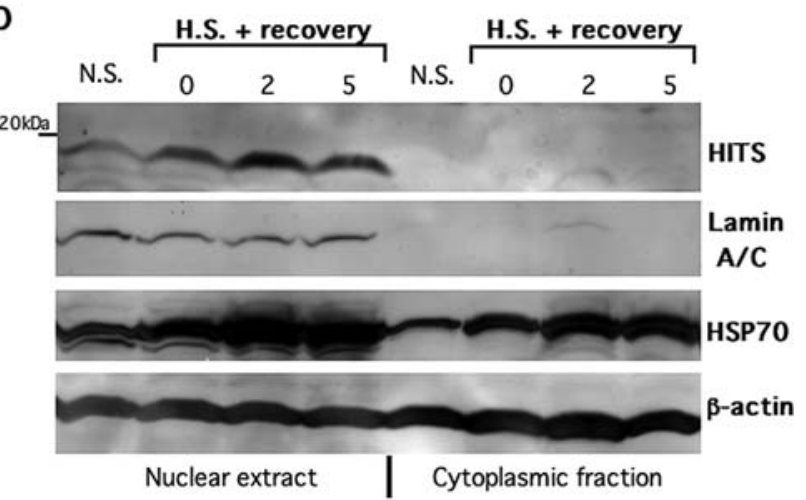

Figure 6. Sequences of the promoter region of HITS gene and heat shock-induced expression of HITS in cultured cells. (A) Genomic sequence of the proximal promoter of HITS -318 from transcription initiation site to +189 in exon 1 is shown. HSF binding sites were underlined. (B) To examine the effects of heat shock treatment on HITS transcription, 293 cells transfected with pGL3-HITS $(-316$ to +189$)$ and pGL3-Basic, respectively were incubated at $42^{\circ} \mathrm{C}$ for $2 \mathrm{~h}$ and recovered at $37^{\circ} \mathrm{C}$ for indicated periods, and processed for luciferase assay. The relative light units (RLU) were calculated after normalization against Renilla luciferase activities of the pRL-TK internal control vector. Values are mean \pm standard deviations in quadruplicates. (C) Effects of heat shock treatment on mRNA expression of HITS in cultured cells. Jurkat cells were incubated at $42^{\circ} \mathrm{C}$ for $2 \mathrm{~h}$ and recovered at $37^{\circ} \mathrm{C}$ for $4 \mathrm{~h}$ (heat shock) or sham treated (untreated), and subjected to RT-PCR analysis. For RT-PCR analysis, cDNA was amplified using specific primer pairs of HITS and B-actin. Amounts of input (3-fold serial dilution of cDNA) are shown above the panels. DNA microarray analysis of these samples is shown in Table II. (D) Effects of heat shock treatment on expression of HITS protein in cultured cells. THP- 1 cells were treated with heat shock (HS) at $42^{\circ} \mathrm{C}$ for $2 \mathrm{~h}$ followed by recovery at $37^{\circ} \mathrm{C}$ for indicated hours and with no heat shock stimulation (NS). Cellular extracts were separated into nuclear and cytoplasmic fractions, and examined by Western blotting for expression of HITS, Lamin A/C (nuclear protein control), HSP70 (heat shock marker) and B-actin.

vector with full length HITS or without an insert (MOCK). In Western blot analysis, HITS was detected as an $\sim 18-\mathrm{kDa}$ protein that was strongly induced by doxycycline treatment on HeLa-Tet-HITS cells, but not on HeLa-Tet-MOCK cells (Fig. 5A). Since TU3A has been reported to inhibit cell growth and induce apoptosis $(2,6)$, we tested the effects of HITS on drug resistances and responses to growth factors using this inducible expression system. At first, HeLa-TetMOCK and -HITS cells were treated with various cytotoxic agents such as paraquat (oxidative stress), etoposide (inhibitor of the topoisomerase II), fluorouracil (5-FU: anti-metabolite) and cisplatin (CDDP: cross-linking of DNA). Drug resistance was determined by relative numbers of survival cells after 48-h exposure to the respective agents. The results showed no significant differences in cell survival between the doxycycline-induced (ON) and non-induced (OFF) cells in both HeLa-Tet-MOCK and -HITS cell lines (Fig. 5B). Next, we compared the cellular response to growth factors (FCS, FGF-2 and EGF) employing the same system. The results showed that proliferative responses to all growth factors tested were attenuated by the inducible expression of HITS, although the inhibitory effects by HITS were not very potent but statistically significant (Fig. 5C).
Table II. Heat shock-induced changes in expression of FAM107 family genes and HSPs determined by DNA microarray analysis.

\begin{tabular}{|c|c|c|c|}
\hline Gene & $\begin{array}{c}\text { Untreated } \\
\text { signal }\end{array}$ & $\begin{array}{c}\text { Heat-shock } \\
\text { signal }\end{array}$ & $\begin{array}{l}\text { Fold } \\
\text { change }\end{array}$ \\
\hline DKFZp434P116 (HITS) & 652 & 2098 & 3.22 \\
\hline FAM107A (TU3A) & 35 & 53 & 1.65 \\
\hline Heat shock $27 \mathrm{kDa}$ protein 1 & 813 & 4194 & 5.16 \\
\hline Heat shock $40 \mathrm{kDa}$ protein 1 & 3231 & 9417 & 2.91 \\
\hline Heat shock $70 \mathrm{kDa}$ protein $1 \mathrm{~B}$ & 1228 & 5964 & 4.86 \\
\hline Heat shock $105 \mathrm{kDa} \mathrm{B}$ & 4259 & 12099 & 2.84 \\
\hline
\end{tabular}

Fold increases of signal intensity of the FAM107 family genes and HSPs after heat-shock treatment are shown.

Induction of HITS expression by heat shock stimulation. Downregulation of HITS expression in cancer cells seems controlled in transcriptional level because the results from 
A

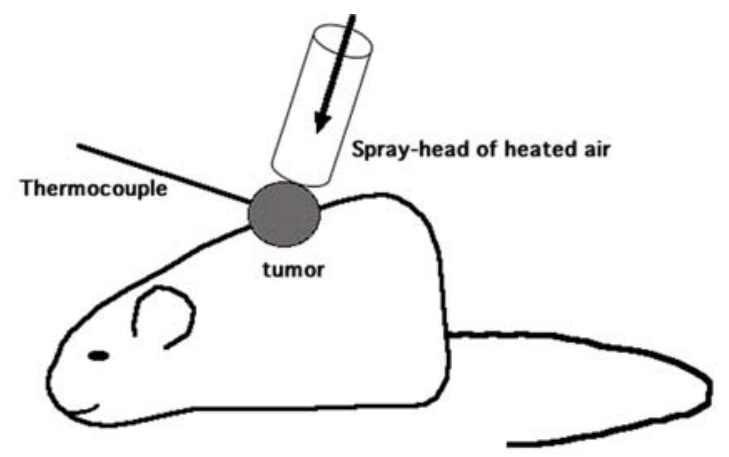

B

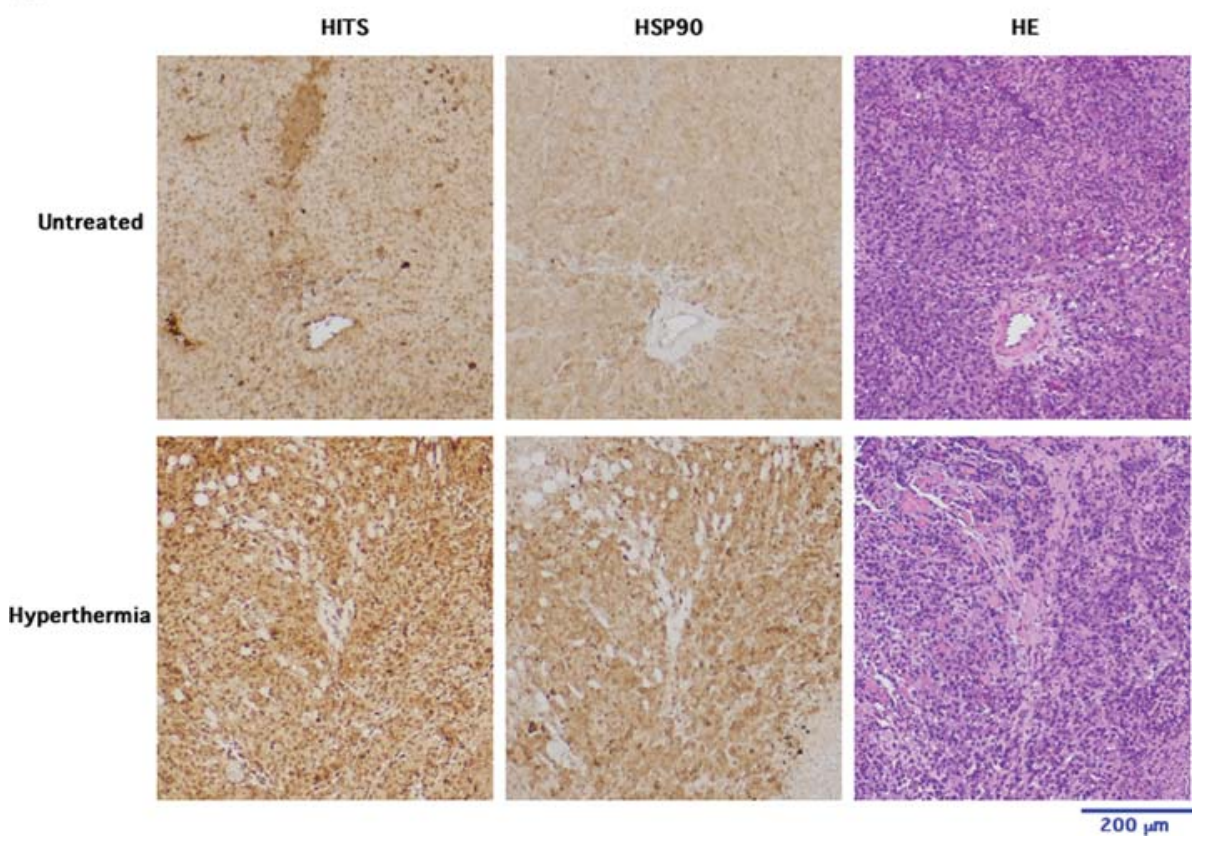

Figure 7. Effects of hyperthermia on expression of HITS and HSP90 in Rat Walker 256 sarcoma cells transplanted in the rat. (A) Schematic representation of hyperthermia using an air heating machine. Rats were placed on the platform of the machine (AOYUE 615) under anesthesia, and the tumor area was covered by the spray-head where heated air was sprayed out. The temperature of the tumor center was monitored by the thermocouple and adjusted to the desired temperature. (B) Rat Walker 256 sarcoma graft of $\sim 2 \mathrm{~cm}$ in diameter was sham treated (upper) or treated (lower) with hyperthermia at $43^{\circ} \mathrm{C}$ for $2 \mathrm{~h}$. Six hours after treatment, the tumors were removed. Serial paraffin sections of the respective tumors were stained with HE and immunostained for HITS and HSP90, respectively.

semi-quantitative RT-PCR analysis showed decreased amount of HITS mRNA in intestinal type gastric adenocarcinomas (Fig. 4E). Then we analyzed the promoter region of HITS gene to identify factors that regulate the transcription of the gene. By database search through http://www.cbrc.jp/ research/db/TFSEARCHJ.html and http://tfbind.ims.utokyo.ac.jp, we found three heat shock elements with an NGAAN motif that recruits heat shock transcription factor (HSF) in the proximal region of HITS gene promoter (Fig. 6A).

To evaluate the effect of heat shock on HITS transcription, first we performed luciferase assays with pGL3 construct with 5'-flanking region $(-316-+189)$ of HITS gene containing three HSF binding sites. Basal transcriptional activity of pGL3-HITS is 30-fold higher than control pGL3-Basic without an insert (Fig. 6B). In comparison with untreated cells, luciferase activity of pGL3-HITS was increased up to $\sim 1.5$-fold by heat shock treatment followed by 4-h recovery at $37^{\circ} \mathrm{C}$ (Fig. 6B). Enhancement of HITS mRNA expression by heat shock treatment was also observed by semi-quantitative RT-PCR and DNA microarray analysis, estimating $\sim 3$-fold increase in mRNA level that is comparable to the effects of other HSPs (Fig. 6C and Table II). Heat shock-induced HITS expression in protein level was detected by Western blot analysis, exhibiting induction of $\sim 18-\mathrm{kDa}$ proteins probed with the anti-HITS Ab in nuclear fractions (Fig. 6D).

Upon these heat shock responses, we further investigated the induction of HITS expression in vivo by immunohistochemical analysis of rat tumor model treated with hyperthermia. Thermotherapy kills or weakens tumor cells, with little effects on healthy cells (16). After treatment at $43^{\circ} \mathrm{C}$ for $2 \mathrm{~h}$ followed by 6-h recovery, HITS as well as HSP90 was markedly induced in the tumor cells compared to those in untreated controls (Fig. 7).

\section{Discussion}

TU3A has been proven to be commonly downregulated or deleted in many types of cancer, such as non-small cell lung, renal cell and prostate cancers and astrocytoma $(1,2,4-6)$. Accordingly TU3A is characterized as a candidate of tumor 
suppressor gene (TSG) because of its typical expression pattern as a TSG and the fact that introduction of TU3A suppresses tumor cell proliferation and induces apoptosis $(2,6,17,18)$. Similar to TU3A, as a member of FAM107, HITS was shown to be decreased or absent in gastric and colorectal cancers and to inhibit tumor cell proliferative responses to growth factors in the present study.

Immunohistochemical examination of HITS in stomach and colorectal tumors exhibited distinct characteristics consistent with a hypothesis that HITS is a TSG. First, expression of HITS decreased in tumors during the process of colorectal adenoma-to-carcinoma sequence (Fig. 3 and Table I). As alterations in the oncogenes and tumor suppressor genes such as adenomatous polyposis coli (APC), K-ras and p53 were frequently involved in a multistep genetic model of colorectal tumorigenesis (19-23), loss of the HITS expression may be involved in the development of colorectal cancers. Second, clear difference in HITS expression was observed between intestinal and diffuse types of gastric adenocarcinomas (Fig. 4 and Table I). Intestinal type cancer is postulated to develop through a sequential pathway from normal mucosa, chronic atrophic gastritis, intestinal metaplasia and then to dysplasia (24-26). On the contrary, diffuse type cancer does not typically arise from recognizable precancerous lesions, and has a higher association with familial occurrence, suggesting a genetic susceptibility (27-29). According to our results that HITS expression was decreased in intestinal type but not in diffuse type gastric adenocarcinomas, HITS may be inactivated or deleted in the development of intestinal type carcinoma from precancerous lesions such as gastric glandular atrophy and intestinal metaplasia. Third, HITS expression was positive in both stomach and colon mucinous adenocarcinomas (Figs. 3B right and 4D), which have been reported to show distinct biological behavior and worse clinical outcome compared to intestinal type adenocaricnomas (30-32).

The most interesting feature concerning HITS expression in tumors was its transcriptional induction by heat shock stimulation. A series of studies has shown that high temperatures can damage cancer cells, usually with minimal injury to normal cells (16). Hyperthermia therefore renders cancer cells to undergo apoptosis in direct response to heat stimulation, while normal cells acclimate to it and maintain their physiological status. Even if the cancer cells do not die immediately, they may become more susceptible to ionizing radiation or to certain chemotherapies. Therefore, hyperthermia is always used with other modalities of cancer therapy, such as radiation and chemotherapy (33). Contrary to clinical benefits of hyperthermia treatment of cancer, induction of HSPs is an undesired consequence in cancer cells $(7,8)$.

HSPs and their relatives are molecular chaperons that facilitate folding of normal proteins and protect them from misfolding and aggregation (34). Their increased expression in tissues that are exposed to various proteotoxic stressors is an adaptive response to sustain cell survival. Therefore, the increased expression of chaperon proteins in many tumor types represents the ability of malignant cells to hold their neoplastic nature in a hostile tumor microenvironment $(35,36)$. In breast cancer, overexpression of HSP70 and HSP90 correlates with poor prognosis $(37,38)$. Overexpression of HSPs also contributes to drug resistance and a poor response to combination chemotherapy (39-42). HSF1 is the master regulator of the heat shock response in eukaryotes, a highly conserved protective mechanism against heat stimulation (43). It functions to facilitate cell survival under different pathophysiological conditions. HSF1 is a powerful multifaceted modifier of cellular malignant transformation by orchestrating a biological network of core cellular functions including proliferation, survival, protein synthesis and glucose metabolism (44-46). Contrary to these oncogenic activities reported in several HSPs and HSF1, HITS seems to function as a tumor suppressor. This is indicated by our observations that forced expression of HITS inhibited the proliferative responses to growth factors, and did not give rise to resistance to various stresses by cytotoxic agents including anti-cancer drugs (Fig. 5).

In conclusion, the present study suggests that HITS, as a member of FAM107, is a potential TSG, with a unique feature of its transcriptional induction by heat shock stimulation. HITS would be useful for tumor diagnosis and for monitoring therapeutic effects of hyperthermia. The molecular mechanism underlying the biological functions of FAM107 is yet to be investigated. C-terminal variable regions of FAM107 carry a coiled-coil domain that has been identified in many nuclear proteins including transcription factors, suggesting a role of FAM107 in regulating gene transcription. An N-terminal conserved domain DUF1151 may play a role in interacting with other proteins to transduce cellular signals. Investigating molecular interactions between FAM107 family proteins and other proteins as well as generating genetic mutant animals are necessary to clarify molecular and physiological functions of FAM107. We are presently investigating fruit flies with genetic alterations of CG9328, Drosophila homolog of FAM107 (Fig. 1A), and have observed putative genetic interaction between CG9328 and Ras-MAPK mediated signaling cascade. Such investigation will lead to the elucidation of the physiological function and the putative mechanism of tumor suppressor effects of FAM107 family of proteins.

\section{Acknowledgements}

We thank Atsuko Asaka, Kazumi Tanaka and Yumiko Hoshiba for their technical assistance. This study was supported by Grants-in-Aids for Scientific Research from the Japanese Ministry of Education, Science, Sports, Technology and Culture, Hokkoku Cancer Foundation and Grants for Promoted Research (S2008-1), Collaborative Research (C2010-6), Project Research from the High-Tech Research Center (H2010-11) of Kanazawa Medical University.

\section{References}

1. Yamato T, Orikasa K, Fukushige S, Orikasa S and Horii A: Isolation and characterization of the novel gene, TU3A, in a commonly deleted region on 3 p $14.3 \otimes$ p 14.2 in renal cell carcinoma. Cytogenet Cell Genet 87: 291-295, 1999.

2. Wang L, Darling J, Zhang JS, et al: Loss of expression of the DRR 1 gene at chromosomal segment 3 p21.1 in renal cell carcinoma. Genes Chromosomes Cancer 27: 1-10, 2000.

3. Awakura Y, Nakamura E, Ito N, Kamoto T and Ogawa O: Methylation-associated silencing of TU3A in human cancers. Int J Oncol 33: 893-899, 2008.

4. Van den Boom J, Wolter M, Blaschke B, Knobbe CB and Reifenberger G: Identification of novel genes associated with astrocytoma progression using suppression subtractive hybridization and real-time reverse transcription-polymerase chain reaction. Int J Cancer 119: 2330-2338, 2006. 
5. Vanaja DK, Ballman KV, Morlan BW, et al: PDLIM4 repression by hypermethylation as a potential biomarker for prostate cancer. Clin Cancer Res 12: 1128-1136, 2006.

6. Liu Q, Zhao XY, Bai RZ, et al: Induction of tumor inhibition and apoptosis by a candidate tumor suppressor gene DRR1 on 3p21.1. Oncol Rep 22: 1069-1075, 2009.

7. Jolly $\mathrm{C}$ and Morimoto RI: Role of the heat shock response and molecular chaperones in oncogenesis and cell death. J Natl Cancer Inst 92: 1564-1572, 2000

8. Whitesell L and Lindquist SL: HSP90 and the chaperoning of cancer. Nat Rev Cancer 5: 761-772, 2005.

9. Mai W, Kawakami K, Shakoori A, et al: Deregulated GSK3, sustains gastrointestinal cancer cells survival by modulating human telomerase reverse transcriptase and telomerase. Clin Cancer Res 15: 6810-6819, 2009.

10. Jass JR, Sobin LH and Watanabe H: The World Health Organization's histologic classification of gastrointestinal tumors. A commentary on the second edition. Cancer 66: 2162-2167, 1990 .

11. Shibata A, Longacre TA, Puligandla B, Parsonnet J and Habel LA: Histological classification of gastric adenocarcinoma for epidemiological research: concordance between pathologists. Cancer Epidemiol Biomarkers Prev 10: 75-78, 2001.

12. Suzuki R, Kohno H, Sugie S and Tanaka T: Sequential observations on the occurrence of preneoplastic and neoplastic lesions in mouse colon treated with azoxymethane and dextran sodium sulfate. Cancer Sci 95: 721-727, 2004.

13. Ougolkov A, Zhang B, Yamashita K, et al: Associations among $\mathrm{B}-\mathrm{TrCP}$, an E3 ubiquitin ligase receptor, $\mathrm{B}$-catenin, and $\mathrm{NF}-\kappa \mathrm{B}$ in colorectal cancer. J Natl Cancer Inst 96: 1161-1170, 2004.

14. Nakajima H, Asai A, Okada A, et al: Transcriptional regulation of ILT family receptors. J Immunol 171: 6611-6620, 2003.

15. Lauren P: The two histological main types of gastric carcinoma: diffuse and so-called intestinal-type carcinoma. An attempt at a histo-clinical classification. Acta Pathol Microbiol Scand 64: $31-49,1965$

16. Van der Zee J: Heating the patient: a promising approach? Ann Oncol 13: 1173-1184, 2002.

17. Kholodnyuk ID, Kozireva S, Kost-Alimova M, Kashuba V, Klein $G$ and Imreh $S$ : Down regulation of $3 p$ genes, LTF, SLC38A3 and DRR1, upon growth of human chromosome 3mouse fibrosarcoma hybrids in severe combined immunodeficiency mice. Int J Cancer 119: 99-107, 2006.

18. Zhao XY, Liang SF, Yao SH, et al: Identification and preliminary function study of xenopus laevis DRR1 gene. Biochem Biophys Res Commun 361: 74-78, 2007.

19. Fearon ER and Vogelstein B: A genetic model for colorectal tumorigenesis. Cell 61: 759-767, 1990

20. Rubinfeld B, Souza B, Albert I, et al: Association of the APC gene product with ß-catenin. Science 262: 1731-1734, 1993.

21. Fodde R, Kuipers J, Rosenberg C, et al: Mutations in the APC tumour suppressor gene cause chromosomal instability. Nat Cell Biol 3: 433-438, 2001.

22. Grady WM and Markowitz SD: Genetic and epigenetic alterations in colon cancer. Annu Rev Genomics Hum Genet 3: 101-128, 2002.

23. Rajagopalan H, Nowak MA, Vogelstein B and Lengauer C: The significance of unstable chromosomes in colorectal cancer. Nat Rev Cancer 3: 695-701, 2003

24. Correa P: Human gastric carcinogenesis: a multistep and multifactorial process - First American Cancer Society Award lecture on cancer epidemiology and prevention. Cancer Res 52: 6735-6740, 1992.

25. El-Omar EM, Carrington M, Chow WH, et al: Interleukin-1 polymorphisms associated with increased risk of gastric cancer. Nature 404: 398-402, 2000.

26. Machado JC, Figueiredo C, Canedo $\mathrm{P}$, et al: A proinflammatory genetic profile increases the risk for chronic atrophic gastritis and gastric carcinoma. Gastroenterology 125: 364-371, 2003.
27. Guilford P, Hopkins J, Harraway J, et al: E-cadherin germline mutations in familial gastric cancer. Nature 392: 402-405, 1998.

28. Kim IJ, Kang HC, Shin Y, et al: A TP53-truncating germline mutation $(\mathrm{E} 287 \mathrm{X})$ in a family with characteristics of both hereditary diffuse gastric cancer and Li-Fraumeni syndrome. J Hum Genet 49: 591-595, 2004.

29. Oliveira C, Ferreira P, Nabais S, et al: E-cadherin (cdh1) and p53 rather than Smad4 and caspase-10 germline mutations contribute to genetic predisposition in Portuguese gastric cancer patients. Eur J Cancer 40: 1897-1903, 2004.

30. Kawamura H, Kondo Y, Osawa S, et al: A clinicopathologic study of mucinous adenocarcinoma of the stomach. Gastric Cancer 4: 83-86, 2001.

31. Perez RO, Bresciani BH, Bresciani C, et al: Mucinous colorectal adenocarcinoma: influence of mucin expression (Muc1, 2 and 5) on clinico-pathological features and prognosis. Int J Colorectal Dis 23: 757-765, 2008.

32. Xie L, Villeneuve PJ and Shaw A: Survival of patients diagnosed with either colorectal mucinous or non-mucinous adenocarcinoma: a population-based study in Canada. Int J Oncol 34: 1109-1115, 2009.

33. Wust P, Hildebrandt B, Sreenivasa G, et al: Hyperthermia in combined treatment of cancer. Lancet Oncol 3: 487-497, 2002.

34. Wegele H, Muller L and Buchner J: Hsp70 and hsp90-a relay team for protein folding. Rev Physiol Biochem Pharmacol 151: 1-44, 2004.

35. Takayama S, Reed JC and Homma S: Heat-shock proteins as regulators of apoptosis. Oncogene 22: 9041-9047, 2003.

36. Rohde M, Daugaard M, Jensen MH, Helin K, Nylandsted J and Jaattela M: Members of the heat-shock protein 70 family promote cancer cell growth by distinct mechanisms. Genes Dev 19: 570-582, 2005.

37. Jameel A, Skilton RA, Campbell TA, Chander SK, Coombes RC and Luqmani YA: Clinical and biological significance of HSP89 alpha in human breast cancer. Int J Cancer 50: 409-415, 1992.

38. Yano M, Naito Z, Tanaka S and Asano G: Expression and roles of heat shock proteins in human breast cancer. Jpn J Cancer Res 87: 908-915, 1996.

39. Ciocca DR, Clark GM, Tandon AK, Fuqua SA, Welch WJ and McGuire WL: Heat shock protein hsp70 in patients with axillary lymph node-negative breast cancer: prognostic implications. J Natl Cancer Inst 85: 570-574, 1993

40. Nanbu K, Konishi I, Mandai M, et al: Prognostic significance of heat shock proteins hsp70 and hsp90 in endometrial carcinomas. Cancer Detect Prev 22: 549-555, 1998.

41. Trieb K, Gerth R, Holzer G, Grohs JG, Berger P and Kotz R: Antibodies to heat shock protein 90 in osteosarcoma patients correlate with response to neoadjuvant chemotherapy. $\mathrm{Br} \mathrm{J}$ Cancer 82: 85-87, 2000.

42. Foster CS, Dodson AR, Ambroisine L, et al: Hsp-27 expression at diagnosis predicts poor clinical outcome in prostate cancer independent of ets-gene rearrangement. Br J Cancer 101: 1137-1144, 2009

43. Westwood JT, Clos J and Wu C: Stress-induced oligomerization and chromosomal relocalization of heat-shock factor. Nature 353: 822-827, 1991.

44. Dai C, Whitesell L, Rogers AB and Lindquist S: Heat shock factor 1 is a powerful multifaceted modifier of carcinogenesis. Cell 130: 1005-1018, 2007.

45. Min JN, Huang L, Zimonjic DB, Moskophidis D and Mivechi NF: Selective suppression of lymphomas by functional loss of Hsf1 in a p53-deficient mouse model for spontaneous tumors. Oncogene 26: 5086-5097, 2007.

46. Zhao YH, Zhou M, Liu H, et al: Upregulation of lactate dehydrogenase a by erbB2 through heat shock factor 1 promotes breast cancer cell glycolysis and growth. Oncogene 28: 3689-3701, 2009. 